\title{
Rainwater Harvesting in Greenhouses Establishments and Use as Irrigation Water
}

\author{
Sedat Boyaci (Corresponding author) \\ Kirsehir Ahi Evran University, Faculty of Agriculture, \\ Department of Biosystems Engineering, Kirsehir, Turkey \\ E-mail: sedat.boyaci@ahievran.edu.tr \\ Sinan Kartal \\ Akdeniz University, Kumluca Vocational School, \\ Department of Plant and Animal Production, Antalya, Turkey \\ E-mail: sinankartal@akdeniz.edu.tr
}

\begin{abstract}
Rainwater collection systems are an alternative water supply method that provides environmental and economic benefits according to traditional water supply methods in arid and semi-arid climates. Rainwater harvested in greenhouse roof by rain gutters can be used to irrigate and grow the plants cultivated in greenhouses. However, rain gutters and storage tanks in greenhouses should be of sufficient size to collect rainwater. Water consumption of plants in the greenhouse should be calculated correctly to determine the storage size in greenhouses. In this study, daily water consumption of tomatoes cultivated in greenhouses not regularly heated in Kumluca district of Antalya province is calculated according to FAO Penman Monteith method. Then, the storage capacity of the remaining part of the falling monthly rainfall used in the greenhouse was determined. As a result of the study, the amount of annual irrigation water harvested from rainfall in Kumluca district where total rainfall is $734.441 / \mathrm{m}^{2}$ was determined as $661.001 / \mathrm{m}^{2}$ based on rainfall factor of 0.9 . In the period between September and June when single crop was grown in the year, the total amount of irrigation water needed by the plants in the not regularly heated greenhouse was calculated as $569.861 / \mathrm{m}^{2}$. Accordingly, it was determined that it is possible to meet all of the irrigation water to be provided to the plant with rainwater harvesting. Depending on the amount of rainwater harvest obtained, it was determined that the storage capacity of $0.40 \mathrm{~m}^{3} / \mathrm{m}^{2}$ in greenhouse is needed. In the study, it was determined that rainwater harvesting may contribute to the development of agricultural activities in areas suffering from water scarcity.
\end{abstract}

Keywords: Greenhouse, Rainwater harvest, crop water requirement, Collection systems.

DOI: $10.7176 / \mathrm{JSTR} / 5-5-01$

\section{Sera İşletmelerinde Yağmur Suyu Hasadı ve Sulama Suyu Olarak Kullanımı}

\section{Özet}

Yağmur suyu toplama sistemleri, su sıkıntısı olan kurak ve yarı kurak iklimlerde geleneksel su sağlama yöntemlerine göre çevresel ve ekonomik faydalar sağlayan alternatif bir su temin yöntemidir. Seralarda yapılan yetiştiricilikte, sera çatısından yağmur olukları yardımıyla toplanacak yağmur suyu hasadı ile yetiştiriciliğgi yapılan bitkilerin sulanarak yetiştirilmesi mümkündür. Ancak yağmur sularının toplanabilmesi için seralarda yağmur oluklarının ve depoların yeterli büyüklükte olması gereklidir. Seralarda depolama büyüklüklerinin belirlenebilmesi için ise serada bitki su tüketiminin doğru hesaplanması gerekmektedir. Yapılan bu çalışmada, Antalya ili Kumluca ilçesi iklim koşullarında düzenli olarak ısıtılmayan seralarda yapılan domates yetiştiriciliğinde aylara bağlı günlük su tüketimi FAO Penman Monteith yöntemine göre hesaplandıktan sonra düşen yağışın serada kullanılan aylık miktarından arta kalan kısmının depolama kapasitesi belirlenmiştir. Yapılan çalışma sonucunda toplam yağış miktarının $734.441 / \mathrm{m}^{2}$ olduğu Kumluca ilçesinde yağış faktörünün 0.9 alınması durumunda yağmur suyu hasadından elde edilecek yıllık sulama suyu miktarının $661.00 \mathrm{l} / \mathrm{m}^{2}$ olduğu belirlenmiştir. Yıl içerisinde tek ürün yetiştiriciliğinin yapıldığı Eylül-Haziran ayları arasındaki dönemlerde düzenli 1sitma yapılmayan serada bitkinin ihtiyacı olan toplam sulama suyu miktarı $569.861 / \mathrm{m}^{2}$ olarak hesap edilmiştir. Buna göre bitkiye verilecek sulama suyunun tamamının yağmur suyu hasadı ile karşılanmasının mümkün olduğu belirlenmiştir. Elde edilen yağmur suyu hasadı miktarına bağlı olarak

1 | $\mathrm{P}$ a g e

www.iiste.org 
serada $0.40 \mathrm{~m}^{3} / \mathrm{m}^{2}$ lik depolama kapasitesine ihtiyaç duyulduğu belirlenmiştir. Yapılan çalışma ile su kıtlığı çeken bölgelerde yağmur suyu hasadının tarımsal faaliyetlerin geliştirilmesine katkıda bulunabileceği belirlenmiştir.

Anahtar kelimeler: Sera, su hasad, bitki su gereksinimi, depolama sistemleri.

\section{Giriş}

Su hasadı, akarsu veya kuyular gibi yaygın olarak kullanılan kaynakların kıt olduğu kurak ve yarı kurak bölgelerde çeşitli amaçlar için yüzey akışa geçen yağmur sularının toplanması ve depolanması anlamına gelir. İnsan, hayvan ve vahşi yaşam için içme suyu sağlamanın yanı sıra, su hasadı sistemleri, bitkisel ürünleri yetiştirmek için ek su sağlayabilir (Frasier, 1980). Yarı kurak ve kurak bölgelerdeki su kaynakları, bitki yetiştiriciliği için en büyük sınırlayıcı faktördür. Bu nedenle yağmur suyunun etkin kullanımı, su kaynakları üzerinde yapılan araştırmaların odak noktalarından biridir (Gao ve ark., 2009). Sera çatısından gelen yağmur suyu, iyi hasat edilmiş ve depolanmışsa, sera içindeki bitkileri sulamak için kullanılabilir. Hasat edilen yağmur suyu için yeterli depolama tesisi sağlanmalıdır. Serada yetiştiriciliği yapılan ve sulama suyu ihtiyacı bilinen bitkiler hasat edilen yağmur suyuyla birlikte yetiştirilebilir (Olaifa, 2015). Sulama suyu birçok bölgede kıt bir faktördür. Bu nedenle, yetiştirilecek ürünün su ihtiyacı hesaplanmalı ve sulama sistemleri dikkatle tasarlanmalıdır. Sera içerisindeki evapotranspirasyon bilgisi, başarılı bitki gelişimi, sulama suyu tüketiminin hesaplanması, yağmur suyunun biriktirilmesi ve depolanması için önemlidir (Zabeltitz, 2011). Akdeniz iklim kuşağında sürdürülebilir tarım açısından gelecekte ortaya çıkacak en büyük sorun temiz su kıtllğı olacaktır. Farklı iklim özelliklerine sahip bölgelerde yağışlı dönemlerde su fazlası ortaya çıkarken, kurak dönemlerde sulama için yeterli su bulunamamaktadır. Serada üretim yapıldığında yağışların meydana geldiği dönemlerde sera çatısına ulaşan yağmur sularının su olukları yardımı ile toplanarak depolanması mümkündür. Yağmur sularının toplanabilmesi için seralarda yağmur oluklarının ve depoların yeterli büyüklükte olması gereklidir. Seralarda depolama büyüklüklerinin belirlenebilmesi için serada bitki su tüketimi doğru hesaplanmalıdır (Baytorun, 2016). Yağmur suyu hasadı, su kitllğından etkilenen bölgelerde etkili alternatif bir su sağlama çözümü olabilir. Son zamanlarda kurak ve yarı kurak alanlarda su temininde birçok faydası ve uygun maliyetleri nedeniyle önemli bir seçenek haline gelmiştir (Liuzzo ve ark., 2016). Küresel 1sınmaya bağlı olarak gelecek on y1llarda Akdeniz sahil şeridinde temiz su kitllı̆g 1 ciddi bir problem olarak ortaya çıkacaktır. Günümüzde Mersin Antalya arasındaki dar sahil şeridinde yapılan düşük teknolojiye sahip seracılıkta ortaya çıkan en büyük sorun sulama suyu yetersizliğidir. Sera üreticisi çok uzak mesafelerden su boruları ile gerekli suyu temin etmek için büyük çaba harcamaktadır. Düşen yağışın hasat edilerek sera sulamasında kullanılması üreticiyi rahatlatacağı gibi üretim maliyetini azaltacaktır (Baytorun ve ark., 2019). (Saltuk, 2019) su kaynakları ve yağış yetersizliğinin üreticinin gelir olanaklarını sınırlandırdığını bildirmiştir. $\mathrm{Bu}$ nedenle sulama için potansiyel yeni kaynakların araştırılması, masraflı kamu suları, aşırı derecede kirlenmiş olabilecek kuyulardan, nehirlerden veya kanal gibi tesislerden elde edilen sulama suyu miktarını azaltarak daha verimli tarımsal faaliyetlerin geliştirilmesine katkıda bulunabilir (Lupia ve ark, 2017). Su varlığına göre ülkeler yılda kişi başına düşen kullanılabilir su miktarı $\left(<1000 \mathrm{~m}^{3}\right.$ : su fakiri, $1000-2000 \mathrm{~m}^{3}$ : su azlığ $1,>8000-1000 \mathrm{~m}^{3}$ : su zengini) olarak sınıflandırılmaktadır (DSİ, 2019). Türkiye su zengini bir ülke değildir. Kişi başına düşen yıllık su miktarına göre ülkemiz su azlığı yaşayan bir ülke konumundadır. Kişi başına düşen yıllık kullanılabilir su miktarı $1519 \mathrm{~m}^{3}$ civarındadır. Ülkemizin yıllık ortalama toplam 112 milyar $\mathrm{m}^{3}$ 'lük kullanılabilir su potansiyelinin $\% 16$ 'sının içme ve kullanmada, $\% 12$ 'sinin sanayide ve $\% 72$ 'sinin ise tarımsal sulamada tüketildiği görülmektedir (DSİ, 2019). Su kaynaklarının yönetiminde en önemli unsur tarımsal sulama olmaktadır. Sulamada su kullanım etkinliğinin arttırılarak su tasarrufu sağlanması büyük önem taşımaktadır (Çakmak ve ark., 2008). Su kaynakları miktarının ve kalitesinin çeşitli sebeplerle azalıyor olması alternatif su arayışını arttırmış ve bu alternatiflerin başında arıtılmış atıksular ile yağmur suyu hasadı yoluyla elde edilen suların tarımda kullanımı gelmektedir (Ahi ve Gültaş, 2018). Su hasadı yapıları, yetersiz yağış ve bu yağışın düzensiz dağılımı nedeniyle su eksikliğinin yaygın olduğu kurak ve yarı-kurak alanlarda ürün alamama riskini düşürerek ve ürün artışını sağlayarak işlenebilir alanların üretkenliğini artırma potansiyeline sahiptirler (Örs ve ark., 2011).

$\mathrm{Bu}$ çalışmada seracılığın yoğun olarak yapıldığı Antalya ilinin Kumluca ilçesinin iklim değerlerinden yararlanılarak düzenli olarak ssitılmayan seralarda FAO-Penman-Monteith yöntemine göre domates bitkisinin su tüketiminin belirlenmesi, yağmur suyu hasadının bitkinin sulama suyu ihtiyacını karşılayabilme potansiyeli ve ihtiyaç duyulan depolama hacminin belirlenmesi amacıyla yürütülmüşsür.

2| P a g e www.iiste.org 


\section{Materyal ve Metot}

\subsection{Kumluca ilçesinin coğarafik ve örtüaltı tarımı açısından açıdan genel özellikleri}

Ülkemizin güneyinde yer alan Antalya ili Kumluca ilçesi 36.3646 enlem ve 30.2978 boylamları arasında yer alır ve deniz seviyesinden yüksekliği 60 m'dir. Ülkemizde niteliklerine göre örtü altı tarım alanlarına bakıldığında toplam 772091 dekar alanın 283283 dekarı Antalya ilinde bulunmaktadır (TÜIK, 2019). Örtüaltı tarımının yoğun olarak yapıldığı Kumluca ilçesinde toplam örtüaltı varlığı 42500 dekar dır. Örtüaltı faaliyetleri bakımından ülkemiz ve Antalya ili açısından önemli bir payı bulunan Kumluca ilçesi Türkiye'deki toplam örtüaltı alanının \%5.5'ini, Antalya ilinin ise \%15'ini oluşturmaktadır. Solanaceous familyasına ait türler (domates, biber ve patlıcan) seralarda yetiştirilen ürünlerin yaklaşık \%60'ını oluşturmaktadır. $\mathrm{Bu}$ türler arasında ise üzerine en çok araştırma yapılan tür domatestir (Katsoulas ve Kittas, 2008). Dünyada ve ülkemizde olduğu gibi Antalya ili Kumluca ilçesindede yetiştiriciliği en fazla yapılan ürün domatestir. İlçede üretimi yapılan ürünler içerisinde toplam 42500 dekar örtüaltı alanının 29850 dekarında (\%70.24) domates üretimi yapılmaktadır.

\subsection{Bitki Su Tüketiminin Belirlenmesi}

Isıtılmayan serada domates bitki su tüketiminin hesaplanması için referans evapotranspirasyon (ETo) değeri adapte edilmiş FAO Penman-Monteith yöntemine göre 1 nolu eşitlik yardımıyla hesaplanmıştır (Allen ve ark., 1998).

$$
\mathrm{ET}_{\mathrm{o}}=\frac{0.408 \times \Delta\left(\mathrm{q}_{\mathrm{RN}}-\mathrm{q}_{\mathrm{RG}}\right)+\gamma \frac{900}{\mathrm{~T}_{\text {mean }}+273} \times \mathrm{v} \times\left(\mathrm{e}_{\mathrm{s}}-\mathrm{e}_{\mathrm{a}}\right)}{\Delta+\gamma(1+0.34 \mathrm{v})}
$$

Eşitlikte: Et $\mathrm{t}_{0}$ : Referans evapotranspirasyon (mm/gün), $\Delta$ : Buhar basıncı eğrisinin eğimi $\left(\mathrm{kPa} /{ }^{\circ} \mathrm{C}\right), \gamma=$ Psikometrik sabite $\left(\mathrm{kPa} /{ }^{\circ} \mathrm{C}\right), \mathrm{q}_{\mathrm{RN}}=$ Bitki yüzeyindeki net radyasyon $\left(\mathrm{MJ} / \mathrm{m}^{2} / \mathrm{gün}\right), \mathrm{q}_{\mathrm{RG}}$ : Toprak 1sıs1 ak1 yoğunluğu çok küçüktür ve normalde ihmal edilebilir $\left(\mathrm{MJ} / \mathrm{m}^{2} /\right.$ gün$), \mathrm{v}=$ Hava hızı $(\mathrm{m} / \mathrm{s}), \mathrm{e}_{\mathrm{s}}=$ Doygun buhar basınc1, $(\mathrm{kPa}), \mathrm{e}_{\mathrm{a}}=$ Gerçek buhar basınc1, $(\mathrm{kPa})$

Yağmur sularının toplanabilmesi için gereksinim duyulan depolama yapılarının yeterli büyüklükte olması gerekmektedir. Planlanacak depolama yapılarının hacminin belirlenebilmesi için gerekli olan bitki su tüketimi ve yağışlardan kazanılan su miktarlarının belirlenebilmesi amacıyla Kumluca ilçesinin uzun yıllık (2007-2018) iklim verileri, Meteoroloji Genel Müdürlüğü kayıtlarından alınmış ve Çizelge $1 \mathrm{de}$ verilmiştir.

Çizelge 1. Kumluca ilçesinin uzun yıllık iklim değerleri

\begin{tabular}{lcccccccccccc}
\hline \multirow{1}{*}{ Parametre } & \multicolumn{10}{c}{ Aylar } \\
\cline { 2 - 12 } & $\mathbf{1}$ & $\mathbf{2}$ & $\mathbf{3}$ & $\mathbf{4}$ & $\mathbf{5}$ & $\mathbf{6}$ & $\mathbf{7}$ & $\mathbf{8}$ & $\mathbf{9}$ & $\mathbf{1 0}$ & $\mathbf{1 1}$ & $\mathbf{1 2}$ \\
\hline $\begin{array}{l}\text { Aylık ort. sıcaklık } \\
\left({ }^{\circ} \mathrm{C}\right)\end{array}$ & 10.0 & 11 & 13.1 & 16.1 & 20.1 & 24.5 & 27.6 & 28.1 & 24.6 & 19.9 & 15.3 & 11.5 \\
$\begin{array}{l}\text { Ort. en yüksek sıcaklık } \\
\left({ }^{\circ} \mathrm{C}\right)\end{array}$ & 16.3 & 17.1 & 19.4 & 22.6 & 25.9 & 30.4 & 33.7 & 34 & 30.7 & 26.6 & 22.3 & 18 \\
$\begin{array}{l}\text { Ort. en düşük sıcaklık } \\
\left({ }^{\circ} \mathrm{C}\right)\end{array}$ & 5.5 & 6.1 & 7.5 & 10.1 & 14.4 & 18.2 & 21.1 & 22 & 18.4 & 14.2 & 10.3 & 7 \\
$\begin{array}{l}\text { Ort. bağıl nem } \\
(\%)\end{array}$ & 80.2 & 79.1 & 74.3 & 71.9 & 70.6 & 63.8 & 59.6 & 60.3 & 63.8 & 68.3 & 75.4 & 80.6 \\
$\begin{array}{l}\text { Toplam yağış } \\
(\mathrm{mm})\end{array}$ & 151.83 & 117.93 & 51.63 & 29.34 & 17.05 & 3.97 & 1.83 & 1.80 & 16.08 & 77.57 & 92.74 & 172.67 \\
$\begin{array}{l}\text { Ort. rüzgar hızı } \\
(\mathrm{m} / \mathrm{sn})\end{array}$ & 2.2 & 2.0 & 2.2 & 2.2 & 2.1 & 2.1 & 2.1 & 2.1 & 2.1 & 2.0 & 2.0 & 2.1 \\
\hline
\end{tabular}

Sera iç ortamındaki sıcaklık değerleri, oluşturulan sera etkisi nedeniyle dış ortamdaki sıcaklık değerlerinden yüksektir. Buna göre seradaki referans evapotranspirasyonun hesaplanması için gerekli olan günlük en yüksek ve en düşük sıcaklık değerleri 2 ve 3, ortalama sıcaklık değeri ise 4 nolu eşitlik yardımıyla hesaplanmıştır. Bunun yanında hesaplamalarda gereksinim duyulan ortalama bağıl nem değeri gün içerisinde havalandırılan serada $\% 80$, seraya ulaşan güneş radyasyonu ise tek katlı polietilen örtü malzemesinin geçirgenliğine bağlı olarak $(\tau) 0.70$ olarak kabul edilmiştir (Zabeltitz, 2011). 
$\mathrm{T}_{\text {gmax }}=\mathrm{T}_{\max }+4$

$\mathrm{T}_{\mathrm{gmin}}=\mathrm{T}_{\min }+2$

$\mathrm{T}_{\text {gmean }}=\left(\mathrm{T}_{\text {gmax }}+\mathrm{T}_{\text {gmin }}\right) / 2$

Eşitliklerde; $\mathrm{T}_{\text {gmax }}$ : Serada ortaya çıkan maksimum sıcaklık $\left({ }^{\circ} \mathrm{C}\right), \mathrm{T}_{\max }$ : Dış ortamdaki maksimum sıcaklık $\left({ }^{\circ} \mathrm{C}\right), \mathrm{T}_{\text {gmin: }}$ Serada ortaya çıkan minimum sıcaklık $\left({ }^{\circ} \mathrm{C}\right), \mathrm{T}_{\min }$ : Dış ortamdaki minimum sıcaklık $\left({ }^{\circ} \mathrm{C}\right)$, $\mathrm{T}_{\text {gmean: }}$ Serada ortaya çıkan ortalama sıcaklık

Serada referans evapotranspirasyon belirlendikten sonra, gerçek evapotranspirasyon $\left(\mathrm{AET}_{\mathrm{c}}\right)$ yalnızca iklimsel etmenlerin değil aynı zamanda toprak ve bitkiye ilişkin özelliklerde dikkate alınarak 5 nolu eşitlik yardımı ile hesaplanmıştır (Zabeltitz, 2011). Eşitlikteki bitki katsayısı $\left(\mathrm{k}_{\mathrm{c}}\right)$ bitkinin farklı evreleri için değişim göstermektedir. Buna göre serada yetiştirilen domates bitkisinin değişik yetişme evrelerine bağlı $\mathrm{k}_{\mathrm{c}}$ katsayıları başlangıç, gelişme, son olmak üzere sırasıyla 0.6-1.2-0.8 olarak alınmıştır (Allen ve ark., 1998). Hesaplamalarda düzenli olarak ısıtılmayan plastik serada üretime Eylül ayında başlanıp, Haziran ayının sonunda son verildiği kabul edilmiştir.

$\mathrm{AET}_{\mathrm{c}}=\mathrm{ET}_{\mathrm{o}} \times \mathrm{k}_{\mathrm{c}}$

Eşitlikte; $\mathrm{AET}_{\mathrm{c}}$ : Gerçek evapotranspirasyon (mm/gün), $\mathrm{k}_{\mathrm{c}}$ : Bitki katsayısı

Serada yetiştirilen domates bitkisinin günlük su tüketimi $\left(\mathrm{CWR}_{\mathrm{d}}\right) 6$ nolu eşitlikten yararlanılarak hesaplanmıştır. Sulama sistemlerinde 0.03-0.1 arasında değişen sulama sistemi kayıp faktörü $\left(\mathrm{l}_{\mathrm{i}}\right)$ damla sulama için 0.04, bitki örtü faktörü $\left(\mathrm{A}_{\text {crop }} / \mathrm{AG}\right)$ ise 0.9 olarak kabul edilmiştir (Zabeltitz, 2011). Bitkinin günlük su gereksinimi $\left(\mathrm{CWR}_{\mathrm{d}}\right)$ belirlendikten sonra, aylık su gereksinimi $\left(\mathrm{CWR}_{\mathrm{m}}\right)$ hesaplanan ayın gün sayısına $\left(\mathrm{d}_{\mathrm{m}}\right)$ bağlı olarak 7 nolu eşitlik yardımı ile hesaplanmıştır.

$\mathrm{CWR}_{\mathrm{d}}=\mathrm{AET}_{\mathrm{c}} \times\left(1+\mathrm{l}_{\mathrm{i}}\right) \times \mathrm{A}_{\text {crop }} / \mathrm{AG}$

$\mathrm{CWR}_{\mathrm{m}}=\mathrm{CWR}_{\mathrm{d}} \times \mathrm{d}_{\mathrm{m}}$

Eşitlikte; $\mathrm{CWR}_{\mathrm{d}}$ : Bitkinin günlük su gereksinimi $\left(\mathrm{mm} /\right.$ gün $=1 / \mathrm{m}^{2} /$ gün$), \mathrm{l}_{\mathrm{i}}$ : Damla sulama sistemi için kayıp faktörü, $\mathrm{A}_{\text {crop }} / \mathrm{AG}$ : Bitki örtü faktörü, $\mathrm{CWR}_{\mathrm{m}}$ : Bitkinin aylık su gereksinimi $\left(1 / \mathrm{m}^{2} / \mathrm{ay}\right), \mathrm{d}_{\mathrm{m}}$ : Hesaplamanın yapıldığa ayın gün sayısı (gün/ay)

\subsection{Depolama Havuzu Kapasitesinin Belirlenmesi}

Depolama kapasitesinin belirlenmesi için gerekli olan hasat edilen aylık yağış miktarı $\left(\mathrm{CV}_{\mathrm{m}}\right)$ aylık yağış miktarı ve düşen yağış miktarının toplanan su miktarına oranına bağlı olarak 8 nolu eşitlik yardımı ile hesaplanmıştır (Zabeltitz, 2011).

$\mathrm{CV}_{\mathrm{m}}=\operatorname{Pre} \times \mathrm{f}_{\mathrm{c}}$

Eşitlikte; $\mathrm{CV}_{\mathrm{m}}$ : Hasat edilen aylık yağış miktarı (1/ $\mathrm{m}^{2} /$ ay), Pre: Aylık yağış miktarı $\left(\mathrm{mm} / \mathrm{ay}=1 / \mathrm{m}^{2} /\right.$ ay), $\mathrm{f}_{\mathrm{c}}$ : Düşen yağış miktarının toplanan su miktarına oranı (plastik sera için 0.9 olarak alınmıştır)

Depolanabilir aylık yağış miktarı $\left(\mathrm{STP}_{\mathrm{m}}\right) 9$ nolu eşitlik yardımı ile hesaplanmıştır. Yapılan hesaplamalarda depolama havuzundan oluşacak buharlaşma kayıpları $\left(\mathrm{EV}_{\text {depo }}\right)$ havuz yüzeyi PE plastikle örtülmüş kabul edilerek sıfır alınmıştır. Hesaplamalar sonucunda depolanabilir aylık yağış miktarı $\left(\mathrm{STP}_{\mathrm{m}}\right)$ pozitif olduğunda depodaki su miktarı artacak, $\mathrm{STP}_{\mathrm{m}}$ negatif olduğunda ise depodaki su miktarı azalacaktır.

$\mathrm{STP}_{\mathrm{m}}=\mathrm{CV}_{\mathrm{m}}-\mathrm{CWR}_{\mathrm{m}}-\mathrm{EV}_{\text {depo }}$

Eşitlikte; STP $\mathrm{m}$ : Depolanabilir aylık yağış miktarı (1/ $\left.\mathrm{m}^{2} / \mathrm{ay}\right), \mathrm{EV}_{\mathrm{depo}}$ : Depolama havuzundan oluşan buharlaşma kaybı $\left(1 / \mathrm{m}^{2} / \mathrm{ay}\right)$

Depolanan yıllık yağış miktarı $\left(\mathrm{STB}_{\mathrm{y}}\right)$ 10, 11 ve 12 nolu eşitlikler yardımıyla belirlenmiştir.

$\mathrm{STB}_{\mathrm{y}}=\mathrm{STP}_{\mathrm{y}}-$ Def $_{\mathrm{y}}$

$\mathrm{STP}_{\mathrm{y}}=\Sigma(+) \mathrm{STP}_{\mathrm{m}}$

4 I $\mathrm{P}$ a g e

www.iiste.org 
$\operatorname{Def}_{\mathrm{y}}=\Sigma(-) \mathrm{STP}_{\mathrm{m}}$

Eşitliklerde; $\mathrm{STB}_{\mathrm{y}}$ : Depolanan yıllık yağış miktarı $\left(1 / \mathrm{m}^{2} / \mathrm{y} 1 \mathrm{l}\right), \mathrm{STP}_{\mathrm{y}}$ : Depolanabilir yıllık yağış miktarı $\left(1 / \mathrm{m}^{2} / \mathrm{y} 1 \mathrm{l}\right)$, Def $_{\mathrm{y}}$ : Yıllık açı miktarı $\left(1 / \mathrm{m}^{2} / \mathrm{y} 1 \mathrm{l}\right)$

\section{Araştırma Sonuçları ve Tartışma}

Kumluca iklim koşullarında düzenli olarak ısıtılmayan seralarda FAO Penman Monteith yöntemine göre hesaplanan aylara bağlı domates bitkisi su tüketimi ve depolanan yağış miktarı değerleri Çizelge 2'de, referans evapotranspirasyon değerleri (ETo $)$ Şekil 1 de ve aylık su tüketimi ve aylık yağış miktarları Şekil 2'de verilmiştir.

Kumluca koşullarında seraya ulaşan radyasyona bağlı olarak en düşük evapotranspirasyon Aralık, en yüksek Temmuz ayında ortaya çıkmaktadır. Isıtma yapılmayan seralarda domates bitkisinin ihtiyaç duyduğu sulama suyu miktarına bakıldığında, ETo değerlerinin 0.78-3.96 1/ $\mathrm{m}^{2} /$ gün arasında değiştiği Çizelge 1 ve Şekil 2 de görülmektedir. Kumluca koşullarında tek ürün yetiştiriciliğinin yapıldığı düzenli olarak 1sıtılmayan seralarda üretime Eylül ayında başlandığı ve Haziran ayında sonlandırıldığ varsayılmıştır. FAO Penman Monteith yöntemine göre hesaplanan aylara bağlı günlük ve aylık su tüketimleri bakıldığında en yüksek su tüketimi Mayıs ayında ortaya çıkarken $(120.47$ 1/m²/ay) Temmuz ve Ağustos aylarında serada ortaya çıkan yüksek sıcaklıkların bitki gelişimini olumsuz etkilemesi nedeniyle üretim yapılmadığından, su tüketimi bu aylar için sıfır olarak hesap edilmiştir.

Çizelge 2. Kumluca koşullarında aylara bağlı domates bitkisi su tüketimi ve depolanan yağış miktarı

\begin{tabular}{lcccccccc}
\hline \multicolumn{1}{c}{ Aylar } & $\begin{array}{c}\text { YağıŞ } \\
\left(1 / \mathrm{m}^{2} / \mathrm{ay}\right)\end{array}$ & $\begin{array}{c}\mathrm{CV} \\
\left(1 / \mathrm{m}^{2} / \mathrm{ay}\right)\end{array}$ & $\begin{array}{c}\mathrm{d}_{\mathrm{m}} \\
(\mathrm{gün})\end{array}$ & $\begin{array}{c}\mathrm{ET}_{\mathrm{o}} \\
\left(1 / \mathrm{m}^{2} / \mathrm{gün}\right)\end{array}$ & $\begin{array}{c}\mathrm{Et}_{\mathrm{c}} \\
\left(1 / \mathrm{m}^{2} / \text { gün }\right)\end{array}$ & $\begin{array}{c}\mathrm{CWR}_{\mathrm{m}} \\
\left(1 / \mathrm{m}^{2} / \mathrm{ay}\right)\end{array}$ & $\begin{array}{c}\mathrm{STP}_{\mathrm{m}} \\
\left(1 / \mathrm{m}^{2} \text { ay }\right)\end{array}$ & $\begin{array}{c}\text { STP } \\
\text { depolama }\end{array}$ \\
\hline Ocak & 151.83 & 136.65 & 31.00 & 0.86 & 1.04 & 33.41 & 103.24 & 323.29 \\
Şubat & 117.93 & 106.14 & 28.00 & 1.21 & 1.46 & 42.44 & 63.69 & 386.99 \\
Mart & 51.63 & 46.47 & 31.00 & 1.78 & 2.14 & 68.94 & -22.48 & 364.51 \\
Nisan & 29.34 & 26.41 & 30.00 & 2.45 & 2.94 & 91.88 & -65.47 & 299.04 \\
Mayıs & 17.05 & 15.35 & 31.00 & 3.11 & 3.74 & 120.47 & -105.12 & 193.92 \\
Haziran & 3.97 & 3.57 & 30.00 & 3.78 & 2.27 & 70.71 & -67.14 & 126.78 \\
Temmuz & 1.83 & 1.65 & 31.00 & 3.96 & 0.00 & 0.00 & 1.65 & 128.43 \\
Ağustos & 1.80 & 1.62 & 31.00 & 3.64 & 0.00 & 0.00 & 1.62 & 130.05 \\
Eylül & 16.08 & 14.47 & 30.00 & 2.85 & 1.71 & 53.38 & -38.91 & 91.14 \\
Ekim & 77.57 & 69.81 & 31.00 & 1.92 & 1.15 & 37.22 & 32.59 & 32.59 \\
Kasım & 92.74 & 83.47 & 30.00 & 1.13 & 0.68 & 21.19 & 62.27 & 94.86 \\
Aralık & 172.67 & 155.40 & 31.00 & 0.78 & 0.94 & 30.21 & 125.19 & 220.05 \\
\hline
\end{tabular}

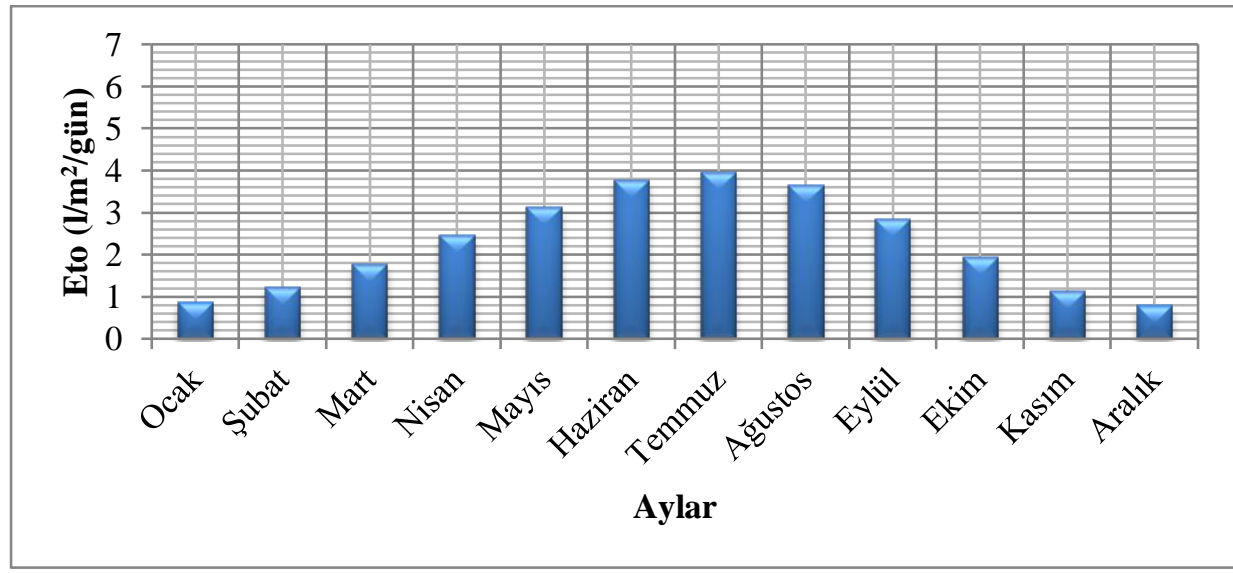

Şekil 1. Kumluca koşullarında aylara göre hesap edilen referans evapotranspirasyon değerleri

Şekil 2'ye bakıldığında serada üretimin yapıldığ 1 yağışlı sonbahar ve kış dönemlerinde su fazlası ortaya çıkarken, ilkbahar ve üretimin sonlandırıldığı yazın ilk ayı olan Haziran ayında düşen yağışlar bitki sulaması için yeterli olmadığı görülmektedir. Kumluca koşullarında Ekim - Şubat arası dönemde düşen 
yağışlar serada yetiştirilen domates bitkisinin su ihtiyacını fazlasıyla karşılarken, Mart ayından Eylül ayına kadar geçen dönemde ise düşen yağışlar serada yetiştirilen domates bitkisinin su tüketimine yeterli olmamaktadır. Bu nedenle, Kumluca bölgesinde yağışlı dönemlerde sera çatısına ulaşan yağmur sularının su olukları yardımıyla toplanarak depolanması ve bitki su tüketiminin hasat edilen yağmur suları ile karşılanabileceği mümkün görülmektedir.

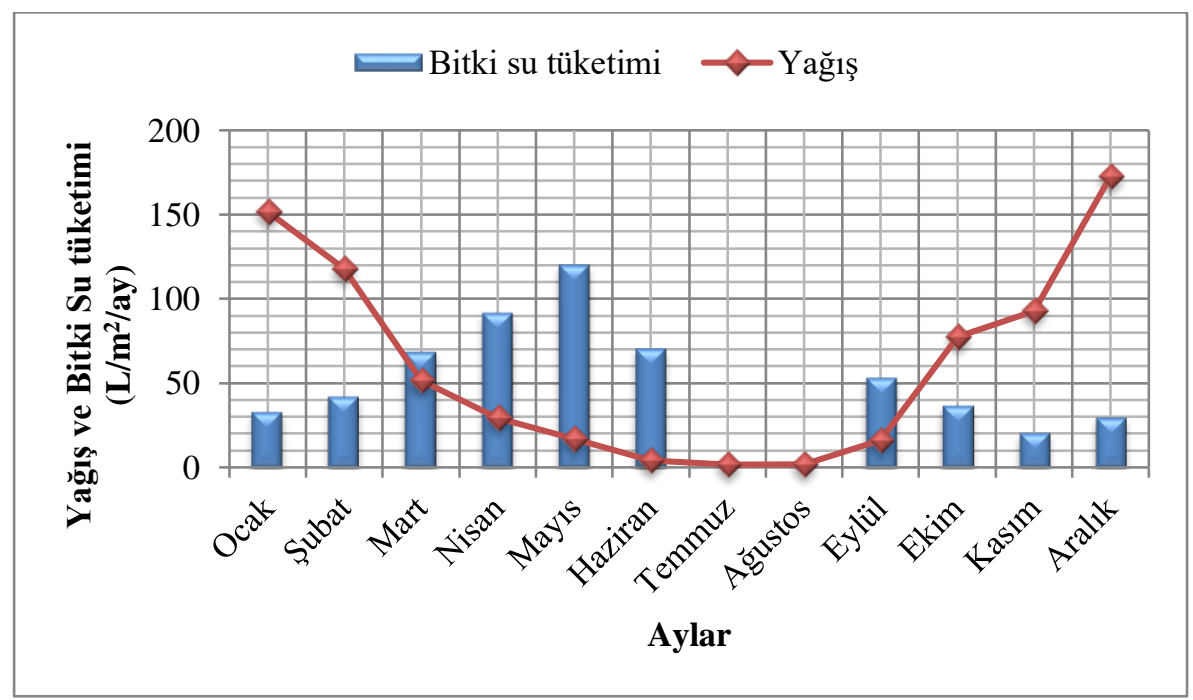

Şekil 2. Kumluca koşullarında isıtılmayan serada domates bitkisinin aylık su tüketimi ve düşen aylık yağış miktarları

Çizelge 2 ye göre Ekim-Mart dönemlerinde seralarda yağmur suyu hasadı yapılması durumunda 386.99 $1 / \mathrm{m}^{2}$ lik bir suyun depolandığı görülmektedir. Buna göre depolama hacmi $1 \mathrm{~m}^{2}$ sera alanına VST $=$ STPy $=386.99\left(1 / \mathrm{m}^{2}\right)=0.40 \mathrm{~m}^{3} / \mathrm{m}^{2}$ dir. Serada Mart ve Eylül ayları arasında bitkinin ihtiyaç duyduğu su mktarının yağmur suyu hasadı ile karşılanacağı görülmektedir.

Toplam yağış miktarının $734.44 \mathrm{l} / \mathrm{m}^{2}$ olduğu ilde yağış faktörünün 0.9 alınması durumunda yağmur suyu hasadından elde edilecek yıllık sulama suyu miktarının $661.00 \mathrm{l} / \mathrm{m}^{2}$ olduğu görülmektedir. Isıtma yapılmayan serada bitkinin ihtiyacı olan toplam sulama suyu miktarı ise $569.86 \mathrm{l} / \mathrm{m}^{2}$ dir. Buna göre bitkiye verilecek sulama suyunun tamamının yağmur suyu hasadı ile karşılanması mümkün görülmektedir.

Pek çok bölgede yağışlı mevsimlerde bitkilerin sulanması için yüksek su fazlası ve kurak mevsimlerde su açığı vardır. Seralarda bitki yetiştirirken, seraların çatılarından akan yağmur suyu toplanıp sulama için kullanılabilir. Tuzlu su varsa, yağmur suyu ile karıştırılabilir ve daha sonra sulama suyu olarak kullanılabilir. Yağmur suyunun toplanması için yeterince büyük oluk ve depolara sahip seralar inşa etmek gereklidir. Yağmur suyuna ve sulama sistemlerine yönelik depolamayı hesaplamak için bitki sulama suyu ihtiyacının bilinmesi gerekmektedir (Zabeltitz, 2011). Yağmur suyu hasadı, kırsal toplumun ve küçük hanelerin yerli kaynaklarına ve ihtiyaçlarına uyarlanabilen nispeten ucuz, küçük ölçekli bir su temini yöntemidir. Çin'in yarı kurak bazı bölgelerinde verimli, sürdürülebilir ve yüksek verimli bir tarım elde etmek için yağmur suyu toplama tarımının geliştirilmesinin esas olduğu bildirilmiştir ( $\mathrm{Li}, 2003$ ). Araştırmacıların yapmış oldukları çalışmalara bakıldığında, (Boyacı ve Kartal, 2019) tarafından Kırşehir ili için yapılan çalışmada, toplam yağış miktarının $388.3 \mathrm{l} / \mathrm{m}^{2}$ olduğu ilde yağış faktörünün 0.9 alınması durumunda yağmur suyu hasadından elde edilecek yıllık sulama suyu miktarının $349.57 \mathrm{l} / \mathrm{m}^{2}$ olduğu bildirmiştir. Yıl içerisinde Nisan-Eylül ayları arasındaki dönemlerde 1sıtma yapılmayan serada bitkinin ihtiyacı olan toplam sulama suyu miktarı ise $568.33 \mathrm{l} / \mathrm{m}^{2}$ dir. Buna göre bitkiye verilecek sulama suyunun \%61.49 unun yağmur suyu hasadı ile karşılanması mümkün görülürken yıl boyunca 1sıtma yapılan serada ise bitkinin ihtiyacı olan toplam $732.05 \mathrm{l} / \mathrm{m}^{2}$ lik sulama suyu ihtiyacının ise $\% 47.74$ ünün yağmur suyu hasadı ile karşılanacağı bildirilmiştir. (Baytorun ve ark., 2019) tarafindan Mersin iklim koşullarında FAO-Radyasyon yöntemine göre hesaplanan su tüketimi ve yă̆ış miktarından gidilerek depolama kapasitesi $0.25 \mathrm{~m} / \mathrm{m}^{2}$ olarak belirlenmiş ve depolanan bu su ile ile Kasım-Mayıs döneminde 7 ay boyunca bitki su ihtiyacının karşılanabileceği belirlenmiştir. Serada Bitki su tüketiminin FAOBlaney-Criddle yöntemine göre hesaplanması durumunda depolama kapasitesi $0.19 \mathrm{~m}^{3} / \mathrm{m}^{2}$ olacak ve Kasım-Nisan dönemindeki 6 aylık sürede bitki su tüketimi karşılanabileceği belirlenmiştir.

6 | P a g e

www.iiste.org 
Yapılan çalışmada da araştırmacıların yapmış oldukları çalışmalara benzer olarak Antalya ili Kumluca ilçesinde uzun yıllık iklim verilerine göre ilçeye düşen yıllık yağış miktarının planlı bir şekilde depolanması halinde domates bitkisinin ihtiyaç duyduğu sulama suyu miktarının tamamının karşılanmasının mümkün olduğu görülmektedir. (Saltuk 2018) sera kurulumunda yaşanan bilgi eksikliğinin seraları kötü tasarlanmış tarımsal üretim yapılarına dönüştürdüğünü bildirmiştir. Bu nedenle yapılacak yağmur suyu hasatında seralara yağmur oluklarının yerleştirilmesinde, depoya suyu taşıyan oluk ve boruların uygun boyutlarda olması, depolanacak su miktarının uygun yöntemler ile tahmin edilerek depolama kapasitesinin belirlenmesi, inşa edilen depo tabanından kaynaklanacak sızma ve depo yüzeyinden meydana gelecek buharlaşma kayıplarını önlemek için deponun uygun malzemeler ile kaplanmasına dikkat edilmelidir. Bu hususlar yağmur suyu hasadının başarısını etkileyeceğinden sistemin doğru çalışabilmesi için seraların plan ve projeleme aşamasında dikkat edilmesi gerekmektedir.

\section{Sonuç}

Yapılan çalışma sonucunda, Antalya ili Kumluca ilçesinde bitki su tüketiminin hesaplanmasında 1sitılmayan serada adapte edilmiş FAO Penman Monteith yöntemine göre birim alan için gereksinim duyulan depolama hacmi $0.40 \mathrm{~m}^{3} / \mathrm{m}^{2}$ olarak belirlenmiştir. Bitki su ihtiyacı ve yağış miktarı karşılaştırıldığında ise yağmur suyu hasadı ile bitkilere verilecek suyun tamamının karşılanabileceği belirlenmiştir. Ancak bu suların doğru yöntemler ile hasat edilebilmesi amacıyla sera çatısından akışa geçen yağmur sularının planlı bir şekilde depolanması gerekmektedir. Bunun için seralarda yağmur oluklarının ve depoların yeterli büyüklükte olması gereklidir. Serada yağmur oluklarının inşa aşamasındaki ilk yatırım maliyeti dışında bakım ve işletme maliyetleri oldukça düşük olması, gelişen teknolojiler ile yağmur oluklarının temini ve montajının kolaylığı, elde edilen yağmur sularının serada kullanılacak sulama sistemi ile bütünleştirilebilir olması ve mevcut su kaynaklarının korunmasına yardımcı olması sistemin avantajları arasında yer almaktadır. Bunun yanında depolanan suların içerisinde bulunabilecek sediment ve depolama esnasında oluşacak kirletici risk faktörlerinin en aza indirilmesi gerektiğinden sulama sitemine verilmeden önce bu suların filtre edilmesi gerekmektedir.

\section{Kaynakça}

Ahi, Y., \& Gültaş, H.T. (2018). Tarımsal Su Yönetiminde Mevcut Teknik ve Teknolojiler. Tarım ve Mühendislik, (1), 72-76.

Allen, G., Pereira, LS., Raes, D., \& Smith, M. (1998). Crop evapotranspiration, Guidelines for computing crop water requirements. FAO irrigation and drainage paper No. 56 FAO, Rome

Baytorun, A.N. (2016). Seralar. Nobel Akademik Yayinc1lık. 415s.

Baytorun, A.N., Zaimoğlu, Z., \& Ünlü, M. 2019. Determination of Harvesting and Storage Capacity of Rain Water in Greenhouse Establishments. Turkish Journal of Agriculture - Food Science and Technology, 7(1), 22-29.

Boyac1, S., \& Kartal, S. (2019). Rainwater Harvesting on Greenhouse Roof and Use in Irrigation. International Journal of Research - Granthaalayah, (7), 93-100. DOI: 10.5281/zenodo.2580547.

Çakmak, B., Yıldırım, M., \& Aküzüm, A. (2008). Türkiye'de Tarımsal Sulama Yönetimi, Sorunlar ve Çözüm Önerileri. TMMOB 2. Su Politikaları Kongresi, Ankara/TURKEY.

DSI (2019). General Directorate of State Hydraulic Works. Retrieved from [Online]. Available at: http://www.dsi.gov.tr/toprak-ve-su-kaynaklari (2019).

Frasier, GW. (1980). Harvesting Water for Agricultural, Wildlife, and Domestic Uses. J. Soil Water Cons. (35), 125-128.

Gao, P., Li, Z.J., Zhang, G.C., \& Liu, ZX. (2009). Rainwater Efficient Use of the Cellar-Greenhouse System on Slope Land in Hilly Semi-Arid Area of North China. Plant Soil Environment, (55), 146-153. 
Katsoulas, N., \& Kittas, C. (2008). Impact of Greenhouse Microclimate on Plant Growth and Development With Special Reference To The Solanaceae. The european journal of plant science and Biotechnology. (2), 31-44.

Li, XY. (2003). Rain Water Harvesting for Agriculture Production in The Semiarid Loess Region of China. Food, Agriculture and Environment, (1), 282-285.

Liuzzo, L., Notaro, V., \& Freni, G. (2016). A Reliability Analysis of a Rainfall Harvesting System in Southern Italy. Water, (8), 1-20. DOI:10.3390/w8010018

Lupia, F., Baiocchi, V., Lelo, K., \& Pulighe, G. (2017). Exploring Rooftop Rainwater Harvesting Potential for Food Production in Urban Areas. Agriculture, (7), 1-17. DOI:10.3390/agriculture7060046

Olaifa, O.P., Abegunrin, T.P., Chukwudebe, E.P., Zaccheaus, O. S., Balogun, A.C., \& Ande, SA. (2015). Incorporating Rain Water Harvesting into the Greenhouse Farming. Journal of Information Engineering and Applications. (5), 84-88.

Örs, İ., Safi, S., Ünlükara, A., \& Yürekli, K. (2011). Su Hasadı Teknikleri, Yapıları ve Etkileri. Tarım Bilimleri Araştırma Dergisi, (4), 65-71.

Saltuk, B. (2018). Current Situation in Mediterranean Greenhouses and a Structural Analysis Example (Mersin Province). Fresenius Environmental Bulletin, 27, 9954-9961.

Saltuk, B. (2019). Determination of Greenhouse Potential in Siirt Province and Districts by Using GIS and Recommendations to Producers. Avrupa Bilim ve Teknoloji Dergisi, (15), 343-350. DOI: 10.31590/ejosat.526157

TÜİK, (2019). Bölgesel istatistikler. https://biruni.tuik.gov.tr/bolgeselistatistik/

Zabeltitz, vC., (2011). Integrated Greenhouse Systems for Mild Climates. Springer-Verlag Berlin Heidelberg. 360p. 